\section{Does the Performance on Principles of Economics \\ Courses Affect the Overall Academic Success of Undergraduate Business Majors?}

\begin{abstract}
Using a sample of 1,339 graduates from an accredited business school and the maximum likelihood technique, this paper explores the relationship between overall academic success and performance on the Principles of Economics courses. The estimated model, which also includes some demographic variables, shows that the rank of professors teaching the course, age of students, and the number of credits earned do not influence business majors' overall academic success. However, the grades earned on the Principles of Economics courses, gender, ethnicity, the major in which the student is enrolled, the number of years the student takes to graduate, as well as whether or not the student is completing a minor significantly affect the overall academic success or the final GPA of business majors.
\end{abstract}

\section{Introduction}

What are the determinants of success for undergraduate business majors? Does the performance on Principles of Economics courses and the learning outcomes achieved in a these courses facilitate learning in other courses and therefore promote student success in the business programme? Testing the relationship between overall GPA and the grade earned in the Principles of Economics courses can be interpreted as trying to determine if there are spillover effects between the
Principles of Economics courses and other courses in the business degree curriculum. Using a similar analogy made by Guest and Vecchio (2003), the argument can be made that because the Principles of Economics courses teach students about the relationship between sectors of the economy, and because these introductory economics courses are prerequisite courses for courses in many other disciplines (e.g. Finance, Marketing, and International Business), when students complete these introductory economics courses and begin to think like economists, the relational level of cognitive complexity that is achieved could facilitate their learning in courses thereafter, helping them to integrate relevant points into a coherent structure. This could help to improve their explanation of causation between factors as well as their ability to analyse, relate and apply. Guest and Vecchio (2003) however imply that the extent to which such externalities exist in teaching and learning depend on how closely the topics are related, what fundamental concepts, methods of analysis and ways of understanding are common to all of the topics. We believe there could be spillovers between the topics in Principles of Economics courses and the topics in International Business, Finance, and Accounting as the method of analysis and the ways of understanding are common. The speculation gains additional strength when reference is made to the research by Didia and Hasnat (1998) in which a sample of 210 students was used to determine the factors that affected the performance in the university introductory finance course. Among the independent variables were the Principles of Economics courses. The ordinary least squares and ordered-probit estimation techniques reveal a strong positive relationship between performance in the Finance course and Principles of Microeconomics and Macroeconomics courses. As indicted by Didia and Hasnat (1998: 105), 'the results suggest that business programs may have a justification for requiring students to complete Principles of Economics... before they take introductory finance courses.' Because of the above, we believe that the performance of students on the Principles of Economic courses could be correlated with their overall performance and hence grades earned in these courses could serve as a useful predictor of a student's overall success in the business curriculum.

Research of this nature is not new as a paper by Nieswiadomy (1998) tested what may at first appear to be an 'artificial' relationship between Law School Admission Test (LSAT) scores and 'majors' of college graduates taking this test. Using 1994-1995 LSAT data, Nieswiadomy (1998) found that when compared to engineering, history, English, finance, political science, psychology, accounting, communications, sociology, and business administration majors, economics majors performed at or near the top of all majors taking LSAT. In fact, the test was repeated by Nieswiadomy (2006) with students from 29 majors and the conclusions were similar. 
The paper is structured as follows. The next section provides an overview of several published studies that examine intellectual and non-intellectual factors that may have value in predicting academic success as well as a review of studies that specifically address a variety of potential determinants of student performance in universities, business schools and in certain courses. We then describe the data used in this research which contain academic and demographic information on 1,339 recent graduates from an AACSB-accredited business school with undergraduate degrees in nine majors including Economics. Although close to 6,500 students graduated from the business school during this period, and all completed Principles of Economics Courses, we limited the sample to only those students that completed the Principles of Economics courses at Florida Atlantic University because we wanted to remove extraneous factors that could be present in the other institutions where students may have completed these courses. We then propose a method for analysing the data to detect relationships between the available variables for the sample. The final section describes the results and summarises the findings of this analysis.

\section{Literature review}

Numerous published studies have considered a variety of potential predictors of academic success for college students and different techniques have been used in these studies. Some of these studies focused on variables that attempted to measure students' non-intellect variables, while others have used a combination of intellectual and non-intellectual variables. Also, some studies have used samples from the entire university while others have focused on students in a single college, discipline or course. Although not common, as most studies have focused on undergraduate students, there have also been a few studies that focused on students seeking advanced degrees.

An early study by Rubin (1977) on the factors that affect academic success of business or economics majors, focused mostly on the socioeconomic variables, and included the following independent variables: the education of the parents, hours per week studied (excluding class time), students' earnings, family size and the number of times families moved. The estimated equation did not produce a good fit, and furthermore some of the a priori assumptions did not hold. For example the assumption that the education of parents is positively correlated with their child's academic success did not hold for either parent. Also, the assumption that students who worked outside the school they attend make lower grades, perhaps because their study time is more limited, did not hold. However the study did prove that study-time is important in enhancing students' grades and that there is a significant negative relationship between the numbers of times a family moves and academic success, and family size and academic success of business and economics majors.
Along the same line as the Rubin (1977) study , non-intellectual variables have been included in studies by Dolan (2008), Ullah and Wilson (2007), Nonis et al. (2005) and Wolfe and Johnson (1995). Along with the usual demographic variables, Dolan

(2008) included the 'skills' that minority students need in order to achieve academic success at the college and university level. Dolan's most important conclusion was that isolation and alienation impacted the academic success of minority students negatively.

Focusing on gender, Ullah and Wilson (2007) concluded that male students' relationships with peers influence their academic achievement negatively. The study by Nonis et al. (2005) investigates the impact of non-intellectual variables such as demographics, personality and behavior on academic success for students who are early and also those that are late in their undergraduate career. After controlling for intellectual variables, Nonis et al. (2005: 57) conclude that non-intellectual variables explained between $16 \%$ and $23 \%$ of the variance in academic success of 269 business students.

Using a sample of 201 psychology students, the Wolfe and Johnson (1995) study shows that average grade earned in high school entrants, SAT scores and self-control are significant predictors of academic success. Their study focused on personality variables as 32 of these variables were included in the study. From the Wolfe and Johnson (1995) study, it was recommended that for college admission decisions, self-control or conscientiousness be systematically assessed and used in the process.

Earlier studies by Willingham (1985), Young and Barrett (1992), Cabrera, Nora and Castaneda (1993), Mouw and Kkanna (1993), Eimers and Pike (1997) and Noble et al. (1999) provide evidence that intellectual variables can be useful predictors of overall academic success for college students (not necessarily business majors). The intellectual variables include ACT and SAT scores, high school grades, and various measures of writing, quantitative and technology skills. Studies that focus on the intellectual variables of business majors include Brookshire and Palocsay (2005) and Smith and Schumacher (2006). Both studies singled out the effects of intellectual variables such as SAT scores, percentile rank in high school graduating class, scores on college mathematics placement exams, grades in specific general education courses, and college grade point averages on the success of students in an introductory management science course and in an actuarial studies programme, respectively. The conclusion from theses studies is that intellectual variables are good predictors of academic success for college students in general and business school students in particular. 
Other more recent studies that focus on factors affecting overall academic success of college student include Vivo and Franco (2008) and Vandamme, Meskens and Superby (2007). Vivo and Franco (2008) use the receiver operating characteristic (ROC) curve that produces a standard method to measure the accuracy for the academic success predictors. ROC analysis focuses on university entrance factor for predicting students' academic success. Vandamme, Meskens and Superby (2007) apply discriminant analysis, neural networks, random forests and decision trees to predict students' academic success. Using a sample of 533 first-year university students Vandamme, Meskens and Superby (2007) were able to classify students into groups such as 'low-risk' - those students who have a high probability of succeeding;'medium-risk' - students who may succeed thanks to the measures taken by the university; and 'high-risk' - students who have a high probability of failing (or dropping out).

There have been many studies on introductory economics and finance courses. As indicated in the introduction, Didia and Hasnat (1998) used an input-output approach to consider the determinants of grades received in the principles of finance course for 210 students enrolled in seven sections offered in the fall semester 1994 and spring semester 1995 at the State University of New York at Brockport. Their study shows that cumulative GPA, prerequisite course grades in accounting, economics and mathematics, and student age have significant and positive coefficients in both OLS and ordered-probit specifications of their model. Didia and Hasnat (1998) also noted that students with heavier course loads performed significantly better in Principles of Finance than those with lesser course loads. In addition, their results suggest a negative relationship between study effort (time) and performance in the course.

Chan, Shum and Wright (1997) also researched the determinants of Principles of Finance grades using the performances of 56 students in two sections of the course taught by the same instructor during one semester at an unspecified mid-western regional state university. The determinants considered in their study include class attendance, GPA, number of weekly work hours, number of credit hours enrolled, age, gender, major, and self-reported quantitative skill level. Using the TOBIT model, Chan, Shum and Wright (1997) found that class attendance and status as a finance major have positive and significant effects on course grades, but that GPA, course load, number of credit hours currently enrolled, weekly work hours and age are not significant determinants of course grades.

Some of the other articles that focus on the determinants of academic success in the Principles of Finance courses include Johnson, Joyce and Sen (2002), Van Ness, Van Ness and Kamery (1999), Sen et al. (1997) and Ely and Hittle (1990). These articles commonly employ both ordinary least squares (OLS) and ordered-probit regression techniques, focusing on such issues as student effort, full- and part-time status and rank of instructors, declared majors, and mathematical background as determinants of student success in basic finance courses.

With regards to Economics courses, Ballard and Johnson (2004) conclude that factors such as the mathematics skills as measured by the student's score on the mathematics portion of the ACT Assessment Test, whether the student has taken calculus, and the student's score on a test of very basic mathematical concepts, have significant effects in explaining performance in introductory Microeconomics courses. In fact, the findings were the same regardless of whether they use self-reported information from students or official administrative records from the university. A somewhat similar study was conducted by Johnson and Kuennen (2006) that concluded that on-line remedial mathematics reviews improve student performance in introductory Microeconomics courses. Using graded pre- and post-tests to assess student understanding of graphing, systems of linear equations, area, slope, ratios and percentages, Johnson and Kuennen (2006) find that pre- and post-test scores are positively and significantly related to course grade, more so than variables designating which mathematics courses have been taken by students. Also, an Arias and Walker (2004) study that is based on an experiment with Principles of Economics students in which they used total exam points as the dependent variable and a list of independent variables including class size (the variable of interest) to explain student performance, concludes that student performance varies inversely with class sizes.

The research that we have conducted for this paper improves on the early study by Rubin (1977) and the recent study by Dolan (2008) as it includes both intellectual and non-intellectual variables. Our study also improves the study by Nonis et al.(2005) because it uses a larger sample and it includes both intellectual and non-intellectual variables. Nonis et al. (2005) did focus on business majors but only used nonintellectual variables. Also, some of the previous studies focus on the determinants of academic success of individual courses and relatively few focus on the determinants of overall success of college students. In fact, none of the studies specifically focus on the role of Principles of Macroeconomics and Principles of Microeconomics courses as determinants of overall academic success of business majors. The present study attempts to contribute to the understanding of factors affecting overall academic success by examining gender, age, ethnicity and performance in two required core knowledge courses as predictors of academic success for a sample of undergraduate students at an AACSB-accredited business school. 


\section{Data sample}

To investigate factors affecting the academic success of undergraduate business students, a sample of 1,339 grade point averages was obtained from the official university records system at Florida Atlantic University (FAU) for graduates with undergraduate degrees in nine majors, (Accounting, Finance, Health Administration, Hospitality and Tourism Management, International Business, Management,

Management and Computer Information Systems, Marketing, and Real Estate). The students' age, gender, ethnicity, major, minor (if any), total credit hours earned, and grades received in Principles of Economics courses were also collected from the university records. The sample was obtained from a population of 6,499 students that graduated from the Barry Kaye College of Business at FAU between 2000 and 2007.

The Barry Kaye College of Business at FAU is accredited by the Southern Association of Colleges and Schools (SACS), and is a public university located in southeast Florida. As of 2006, FAU had an enrollment of $26,000+$ students, including $6,300+$ full- and part-time business students at the graduate and undergraduate level. The business school is fully accredited through the doctoral level by AACSB

International, the Association to Advance Collegiate Schools of Business. The school can be characterised as a regional commuter school serving a diverse population at multiple campuses over a geographic area along the I-95 corridor of south-east Florida from Port St. Lucie in the north to Fort Lauderdale in the south.

Students can be admitted to the FAU business school only after they reach junior status (60 complete credit hours) and have a minimum grade point average of 2.0 on a 4.0 scale. Along with their major course of study, a student can complete a minor (usually 12 credit hours). This option allows business students to combine courses from different majors and create customised plans of study.

All of these students completed their Principles of Microeconomics (ECO 2023) and Principles of Macroeconomics (ECO 2013) early in their programme, usually during the first (Freshman) and second (Sophomore) years. Some graduates were not required to take these courses because of their high school AP preparation/success in Economics and others completed a combined five-credit Principles of Micro- and Macroeconomics course. Whereas the Principles of Microeconomics course teaches students about consumer behavior, the theory of the firm and the economics of resource use, the Principles of Macroeconomics course provides students with an overview of the basic concepts and techniques of managing the macroeconomy.

A higher level of quantitative analysis and analytical skills is demanded in the Principles of Economics courses than other freshman and sophomore courses, and both courses have the reputation among some students and faculty as 'weed out' courses. Also, Principles of Economics courses are used as prerequisite courses for taking upper level business courses, and many of the concepts taught in the Principles of Economics courses are applied in upper level business courses. The Principles of Economics courses therefore serve as a screening mechanism that tends to identify students who are not adequately prepared for business studies even though they meet the initial admission standards for the Barry Kaye College of Business. Both courses are taught with a common syllabus, grading scheme and test bank to maintain a minimum measure of consistency across instructors. The 1,339 students who graduated from the business school between 2000 and 2007 completed both of the core knowledge courses described above at Florida Atlantic University. The average grade point average (GPA) for these graduates over the study period is 2.90 on a 4.0 scale.

The average grade received by students taking ECO 2013 was 2.571 and ECO 2023 was 2.570 (letter grades converted to the numerical 4.0 scale). The average age of students in the sample was at the time of graduation was 24.71 years. Of the sample, $49.4 \%$ of the graduates were male and $50.6 \%$ were female; $63.9 \%$ were White, $12.1 \%$ were African-American, $16.8 \%$ were Hispanic and $6.6 \%$ were Asian. Additional descriptive statistics for the variables available for this study are provided in Table 1.

Table 1: Descriptive statistics for variables in the sample $N=1,339$

\begin{tabular}{lcc}
\hline CONTINUOUS VARIABLES & MEAN & STANDARD DEVIATION \\
\hline GPA & 2.900 & 0.44 \\
ECO 2013 GRADE & 2.571 & 1.02 \\
ECO 2023 GRADE & 2.570 & 1.00 \\
AGE AT GRADUATION & 24.71 & 4.40 \\
\hline BINARY VARIABLES & COUNT & PER CENT \\
\hline DEMOGRAPHICS & & \\
Female & 678 & 50.6 \\
Male & 661 & 49.4 \\
White & 856 & 63.9 \\
African-American & 162 & 12.1 \\
Hispanic & 225 & 16.8 \\
Asian & 88 & 6.60 \\
Others & 8 & 0.60 \\
MINOR & 470 & 35.1 \\
\hline
\end{tabular}




\section{Statistical analysis method}

The determinants of overall academic success for undergraduate business majors are tested using the following conceptual model:

ADJUSTED GPA $=f(E C O 2013$, Professor's rank in ECO2013, ECO2023, Professor's rank in ECO2023, gender, age, ethnicity, year, major, minor, credits earned)

In this model, overall grade point average at graduation (adjusted to remove the grades in ECO2013 and ECO2023) is a function of grades earned in the core knowledge courses, Principle of Macroeconomics (ECO2013) and Principles of Microeconomics (ECO2023), the professor's rank in the courses, the student's gender, age at graduation, ethnicity, graduation year, the number of credits earned, the students major, and whether or not the student also earned a minor to supplement the major. Professors were ranked as either tenured or non-tenured. Including year of graduation in the model addresses the potential for grade inflation/deflation over the study period.

Several different statistical analysis methods have been used in previous studies of the factors determining academic success or to study the relationships between academic success (typically measured by GPA) and intellectual and non-intellectual predictor variables. Those that investigated the determinants of overall academic success used simple correlation analysis, ANOVA, OLS regression, hierarchical regression and logistical regression. In studies that considered the determinants of success in Principles of Economics courses, the method of analysis included OLS, Probit, ordered-Probit, TOBIT and Heckman's two-stage procedure (Heckman, 1976).

Just like the study by Chan, Shum and Wright (1997) that was described earlier, the data available for the current study present potential sample selection bias. The sample used by Chan, Shum and Wright (1997) was described as censored because some observations of the dependent variable corresponding to known values of the independent variables were not observable. This is because 12 students from the sample withdrew and did not complete the course. These students may have chosen to 'drop' the course rather than 'fail'. Chan, Shum and Wright (1997) used the TOBIT model (Tobin, 1958) and Heckman's two-stage procedure (Heckman, 1976) to address this potential sample selection bias, and found that class attendance and status as a finance major have positive and significant effects on course grades.

The sample available for our study also does not include students who withdrew voluntarily, and in addition it also excludes those who did not maintain the required 2.0 GPA for business majors and were forced to withdraw from the Barry Kaye College of Business before graduation. The data available for the current study was thus a 'truncated' rather than a 'censored' sample and neither the TOBIT or Heckman procedure is appropriate for this situation. Thus, the sample is drawn from a restricted part of the population: the sample is 'truncated from below' with a minimum GPA of 2.0 for all observations and includes only those students that completed both principles courses at Florida Atlantic University. The sample also omitted students who transferred to other schools during their degree programmes at FAU or otherwise voluntarily withdrew from FAU, whether or not they successfully completed the ECO 2013 and ECO 2023 courses. We assume those transfers and withdrawals are randomly distributed and do not bias the remaining sample.

A more formal exposition of the truncated sample problem (following Long (1997)) is summarised below. Assume that the truncated variable $x$ has a normal distribution with mean $\mu$ and standard deviation $\sigma$. The density function of the truncated normal distribution is

$$
f(x \mid a<x<b)=\frac{f(x)}{\Phi\left(\frac{b-\mu}{\sigma}\right)-\Phi\left(\frac{a-\mu}{\sigma}\right)}=\frac{\frac{1}{\sigma} \phi\left(\frac{x-\mu}{\sigma}\right)}{\Phi\left(\frac{b-\mu}{\sigma}\right)-\Phi\left(\frac{a-\mu}{\sigma}\right)}
$$

where $\varphi$ and $\Phi$ are the density and distribution functions of the standard normal distribution. When the truncation is 'from below' (with $a$ in this situation equal to 2.0), the mean of the truncated variable is greater than the true mean of the distribution and the variance is less than the true variance.

In the presence of truncation, ordinary least squares is not an appropriate regression estimator when the goal is to draw inferences about the full population. OLS is, however, adequate if the goal is to draw inferences only from the restricted population. Fitting a regression function with a truncated dependent variable can be accomplished with maximum likelihood estimation (MLE). The log likelihood function when $a$ is the lower limit and $b$ is the upper limit is:

$$
L=-\frac{n}{2} \log \left(2 \pi \sigma^{2}\right)-\frac{1}{2 \sigma^{2}} \sum_{i=1}^{n}\left(y_{i}-x_{i} \beta\right)^{2}-\sum_{i=1}^{n} \log \left[\Phi\left(\frac{b-x_{i} \beta}{\sigma}\right)-\Phi\left(\frac{a-x_{i \beta}}{\sigma}\right)\right] .
$$

Fitting the conceptual model provided above to the data sample using MLE provides the results discussed in the next section.

\section{Results}

Table 2 shows the truncated regression results for the sample of 1,339 business school graduates who took the two principles courses (ECO 2013 and ECO 2023) at FAU.The Wald $\chi^{2}$ statistics for the model (758.61) is significant at the $5 \%$ level, 
Table 2: Truncated regression results obtained from MLE for all business majors completing both ECO 2013 and ECO 2023

\begin{tabular}{|c|c|c|c|}
\hline \multicolumn{4}{|c|}{$\begin{array}{l}\text { Dependent variable }=\text { Adjusted GPA } \\
\qquad N=1,339\end{array}$} \\
\hline & Coefficient & $\begin{array}{l}\text { Standard } \\
\text { error }\end{array}$ & $\underset{\text { z-statistic }}{\text { Wald }}$ \\
\hline ECO2013 (Principles of Macroeconomics) & 0.1458 & 0.0113 & $12.88^{*}$ \\
\hline Professor's Rank in ECO2013 & 0.0038 & 0.0206 & 0.19 \\
\hline ECO2023 (Principles of Microeconomics) & 0.2112 & 0.0118 & $17.84^{*}$ \\
\hline Professor's Rank in ECO2023 & -0.0298 & 0.02412 & -1.23 \\
\hline Age & -0.003 & 0.0024 & -1.25 \\
\hline Female & 0.1376 & 0.0203 & $6.77^{*}$ \\
\hline African American & -0.1756 & 0.0326 & $-5.39 *$ \\
\hline Hispanic & -0.0948 & 0.0275 & $-3.45^{*}$ \\
\hline Asian & -0.0357 & 0.0403 & -0.88 \\
\hline Minor & 0.0798 & 0.0223 & $3.58^{*}$ \\
\hline Year & 0.0172 & 0.0045 & $3.79 *$ \\
\hline Number of Credits Earned & -0.0010 & 0.0006 & -1.68 \\
\hline Finance & 0.0692 & 0.0315 & $2.20^{*}$ \\
\hline Accounting & 0.0895 & 0.0411 & $2.18^{*}$ \\
\hline Hotel Management & 0.0070 & 0.1145 & 0.06 \\
\hline Health Administration & 0.2155 & 0.0436 & $4.95^{*}$ \\
\hline Real Estate & -0.0376 & 0.0859 & -0.44 \\
\hline Marketing & 0.0600 & 0.0320 & 1.87 \\
\hline Economics & 0.1416 & 0.0724 & $1.96^{*}$ \\
\hline International Business & 0.0600 & 0.0360 & 1.67 \\
\hline Management/Computer Information Systems & 0.0464 & 0.0378 & 1.23 \\
\hline Constant & 2.0022 & 0.0915 & $21.89^{*}$ \\
\hline Wald $\chi^{2}$ (22 d.f.) & $758.61^{*}$ & & \\
\hline rough $R^{2}$ & $45.44 \%$ & & \\
\hline
\end{tabular}

Asterisks indicate significance of the coefficients at the $5 \%$ level

thereby causing us to reject the null hypothesis that all coefficients in the model are equal to zero. While the truncated regression does not provide an $R^{2}$ or a pseudo $R^{2}$, an approximation of the degree of association between the dependent variable and the independent variables can be calculated as the square of the correlation between the predicted values and the dependent variable (Long, 1997). The'rough
$R^{2}$ obtained for the estimation indicates that the model accounts for (or 'explains') $45.44 \%$ of the variation in business majors' overall GPA.

The results indicate that the rank of the professor teaching the courses, age of students and the number of credits earned do not influence the overall academic success of students in the business program at FAU. Because age was not a factor, the hypothesis that the older students who bring a wealth of knowledge acquired through employment and/or life experience to the programme should perform better in the business programme, was therefore rejected.

From Table 2, the results show that the grade earned on the Principles of Economics courses, gender, ethnicity, the major in which the student is enrolled, the number of years the student takes to graduate, as well as whether or not the student is completing a minor significantly affect the business students' final GPA. Based on the sample, a one-unit increase in a student's GPA in Principles of Macroeconomics and Principles of Microeconomics courses causes an increase in overall GPA at graduation of 0.1458 and 0.212 respectively, and that the Principles of Microeconomics has a greater impact on overall GPA than Principles of Macroeconomics.

From Table 2, the coefficient for the gender variable indicates that females are about $14 \%$ more likely to graduate with a higher GPA than males. This of course is quite disconcerting because of the emphasis that is placed on ensuring that both males and females have equal opportunities. While the coefficients for African American and Hispanic students indicate that they do not perform as well as White students in the business programme, the fact that the coefficient for Asian students is not significant indicates that the performance of Asian students is similar to that for White students. A dummy variable for White students was not included in the regression and the coefficient for Asian students is not significantly different from the omitted White students. For African American students and Hispanic students, the results indicate that they are about $18 \%$ and $9 \%$ respectively less likely to graduate with a higher GPA than White students. Furthermore, the coefficients indicate that the performance of African American students is the worst compared to all other ethnic groups.

The coefficient for the year variable is positive and significantly different from zero. The conclusion from this is that grades increased or were inflated over the study period. The coefficient for the minor variable is significantly different from zero, suggesting that students who include a minor in their plan of study earn a different GPA from those who do not. For the 'major'variable, dummy variables were used to indicate the students' choice of major, with Management Major being the omitted category. From Table 2, the coefficients for Finance, Accounting, Health Administration, and Economic are significant at the 5\% level and students 
Table 3: OLS regression results obtained for all business majors completing both ECO 2013 and ECO 2023

\begin{tabular}{|c|c|c|c|}
\hline \multicolumn{4}{|c|}{$\begin{array}{l}\text { Dependent variable }=\text { Adjusted GPA } \\
\qquad N=1,339\end{array}$} \\
\hline & Coefficient & $\begin{array}{l}\text { Standard } \\
\text { error }\end{array}$ & t-value \\
\hline ECO2013 (Principles of Macroeconomics) & 0.1302 & 0.01003 & $12.98^{*}$ \\
\hline Professor's Rank in ECO2013 & 0.0003 & 0.01887 & 0.01 \\
\hline ECO2023 (Principles of Microeconomics) & 0.1866 & 0.01020 & $18.29 *$ \\
\hline Professor's Rank in ECO2023 & -0.0259 & 0.02220 & -1.17 \\
\hline Age & -0.0024 & 0.00225 & -1.16 \\
\hline Female & 0.1283 & 0.01871 & $6.86^{*}$ \\
\hline African American & -0.1546 & 0.02913 & $-5.31 *$ \\
\hline Hispanic & -0.0835 & 0.02515 & $-3.32 *$ \\
\hline Asian & -0.0306 & 0.03716 & -0.82 \\
\hline Minor & 0.0758 & 0.02057 & $3.68^{*}$ \\
\hline Year & 0.0163 & 0.00418 & $3.90^{*}$ \\
\hline Number of Credits Earned & -0.0008 & 0.00055 & -1.45 \\
\hline Finance & 0.0621 & 0.02902 & $2.14^{*}$ \\
\hline Accounting & 0.0857 & 0.03834 & $2.23^{*}$ \\
\hline Hotel Management & 0.0064 & 0.10176 & 0.06 \\
\hline Health Administration & 0.1934 & 0.03997 & $4.84^{*}$ \\
\hline Real Estate & -0.0221 & 0.07461 & -0.30 \\
\hline Marketing & 0.0469 & 0.02877 & 1.63 \\
\hline Economics & 0.1354 & 0.06797 & $1.99^{*}$ \\
\hline International Business & 0.0552 & 0.03288 & 1.68 \\
\hline Management/Computer Information Systems & 0.0403 & 0.03447 & 1.27 \\
\hline Constant & 2.0955 & 0.08417 & $24.90^{*}$ \\
\hline$F(21,1317)$ & $52.13^{*}$ & & \\
\hline$R^{2}$ & $45.39 \%$ & & \\
\hline
\end{tabular}

Asterisks indicate significance of the coefficients at the $5 \%$ level

completing these courses of study are expected to perform better than Management Majors.

To add some credibility to the results reported in Table 2, the model was estimated using ordinary least squares and the results reported in Table 3 . The results reported in Table 3 mirror those in Table 2 in that the grades earned in both introductory economics courses, gender, ethnicity, the student's choice of major, and the inclusion of a minor in their course of study have some influence on the overall GPA of business majors.

\section{Conclusions}

The analysis presented in this paper provides useful insight into the factors that could affect the academic success of undergraduate business majors. Previous research on academic success factors suggests that both intellectual and non-intellectual variables may serve as useful predictors of a student's academic success. This study contributes to that line of research by showing that grades earned in a certain area (Principles of Economics courses) that complements the core knowledge in other courses are good predictors of overall academic success. Certain demographic variables (gender and ethnicity) also proved to be useful indicators of students' overall academic success. Overall, the results of this study provide some evidence that information that is readily available from most universities' official records systems can be useful in predicting students' future academic success. Based on this study, we conclude that more attention should be paid to the grades earned on the Principles of Economics courses as they could serve as an 'early warning signal' of academic success or failure. These findings support the contention that these two core knowledge courses may serve as 'weed out' courses in the business school curriculum. Using these courses, faculty and administrators will be able to identify students who could benefit from early intervention.

The sample did not include behavioral or personality variables that other researchers have considered to be important predictors of academic success, but future research may permit these issues to be examined more carefully. The sample did not include a measure of general ability of students that could impact overall ability, which normally is the GPA of incoming students. This information was not available in a uniform manner due to the diversity of the population. Students attending FAU come from over 50 countries, some using SAT for entry while others transfer from universities and colleges. Furthermore, GPA's and letter grades are often not based on the same scales.

\section{References}

Arias, J. J and Walker, D. M. (2004) 'Additional evidence on the relationship between class size and student performance', The Journal of Economic Education, Fall 2004, v35 i4, 311-330.

Ballard, C. L. and Johnson, M. F. (2004) 'Basic math skills and performance in an introductory economics class', The Journal of Economic Education, 3-24. 
Brookshire, R. G. and Palocsay, S. W. (2005) 'Factors contributing to the success of undergraduate business students in management science courses', Decision Sciences Journal of Innovative Education, 3(1), 99-108.

Cabrera, A. F., Nora, A. and Castaneda, M. B. (1993) 'College persistence: structural modeling test of an integrated model of student retention', Journal of Higher Education, 64(2), 123-139.

Chan, K.C., Shum, C. and Wright, D.J. (1997) 'Class attendance and student performance in Principles of Finance', Financial Practice and Education, Fall/Winter, 58-65.

Didia, D. and Hasnat, B. (1998).'The determinants of performance in the university

introductory finance course', Financial Practice and Education, Spring/Summer, Volume 8,

$\# 1,102-107$.

Dolan, T.G. (2008) 'Minority students and college success: challenges and solutions', Education Digest, Vol. 73, Issue 7, 27-30.

Eimers, M.T. and Pike, G. R. (1997) 'Minority and non-minority adjustment to college: differences or similarities?' Research in Higher Education, 38(1), 77-97.

Ely, D. P. and Hittle, L. (1990) 'The impact of math background on performance in managerial economics and basic finance courses', Journal of Financial Education, 19(1), 59-61.

Guest, R and N.Vecchio (2003) 'Are There Learning Spillovers in Introductory Macroeconomics?' International Review of Economics Education, Volume 1, \#1, 36-60. Heckman, J. (1976) 'The common structure of statistical models of truncation, sample selection, and limited dependent variables and a simple estimator for such models', Annals of Economic and Social Measurement, 5, 475-492.

Johnson, D.L., Joyce, P. and Sen, S. (2002) 'An analysis of student effort and performance in the finance principles course', Journal of Applied Finance, Fall/Winter, 67-72.

Johnson, M. and Kuennen, E. (2006) 'On-line mathematics reviews and performance in introductory microeconomics', Journal of Economics and Economic Education Research, 3-22.

Long, J. S. (1997) Regression Models for Categorical and Limited Dependent Variables. Thousand Oaks, CA: Sage Publications.

Mouw, J. and Kkanna, R. (1993) 'Prediction of academic success: a review of the literature and some recommendations', College Student Journal, 27(3), 328-336.

Nieswiadomy, M. (1998) 'LSAT scores of economics majors', The Journal of Economic Education, Volume 29, \#4, 377-379.

Nieswiadomy, M. (2006) 'LSAT scores of economics majors: the 2003-2004 class update', The Journal of Economic Education, Volume 37, \#2, 244-247.

Noble, J., Davenport, M., Schiel, J. and Pommerich, M. (1999) 'Relationship between noncognitive characteristics, high school coursework and grades, and test scores of ACT-tested students', ACT Research Report Series, 99-4, lowa City, IA: American College Testing Program.

Nonis, S. A., Philhours, M., Syamil, A. and Hudson, G. I. (2005) 'The impact of nonintellectual variables on the academic success of business students', Marketing Education Review, 15(3), 51-63.

Rubin, L. S. (1977) 'Socioeconomic and Academic Factors Influencing College Achievement of Economics and Business Majors', Journal of Economic Education, Vol. 8, No. 2, Spring, 124-125.
Sen, S., Joyce, P., Farrell, K. and Toutant, J. (1997) 'Performance in Principles of Finance courses by students with different specializations', Financial Practice and Education, Fall/Winter, 66-73.

Smith, R. M. and Schumacher, P. (2006) 'Academic attributes of college freshmen that lead to success in actuarial studies in a business college', Journal of Education for Business,

(81(5), 256-260.

Tobin, J. (1958) 'Estimation of relationships for limited dependent variables', Econometrica 26(1), 24-36.

Ullah, $\mathrm{H}$ and Wilson, M. A. (2007) 'Students' academic success and its association to student involvement with learning and relationships with faculty and peers', College Student Journal, Part B, Vol. 41, \#4, 1192-1202.

Van Ness, B.F., Van Ness, R.A. and Kamery, R.H. (1999) 'The effects of part-time instruction on grades in Principles of Finance', Financial Practice and Education, Fall/Winter, 105-110.

Vandamme, J. P., Meskens, N. and Superby, J. F. (2007) 'Predicting Academic Performance by Data Mining Methods', Education Economics, Vol. 15, \#4, 405-419.

Vivo, J-M. and Franco, M. (2008) 'How does one assess the accuracy of academic success predictors? ROC analysis applied to university entrance factors', International Journal of Mathematical Education in Science \& Technology, Vol. 39, \#3, 325-340.

Willingham, W.W. (1985) 'Success in College:The Role of Personal Qualities and Academic Ability', New York: The College Board.

Wolfe, R. N. and Johnson, S.D. (1995) 'Personality as a predictor of college performance', Educational and Psychological Measurement, 55(2), 177-185.

Young, J.W. and Barrett, C. A., (1992) 'Analyzing high school transcripts to improve prediction of college performance', The Journal of College Administration, 137(Fall), 25-29.

Contact details

Rupert G. Rhodd (correspondence author)

College of Business

2912 College Avenue

Davie, FL 33314

USA

Email: Rhodd@fau.edu

Sandra M. Schrouder

Florida Atlantic University

School of Public Administration

Marcus T. Allen

College of Charleston

School of Business and Economics 